\title{
XLI. The heats of vaporization of liquids
}

\section{S. Roslington Milner B.Sc.}

To cite this article: S. Roslington Milner B.Sc. (1897) XLI. The heats of vaporization of liquids, Philosophical Magazine Series 5, 43:263, 291-304, DOI: 10.1080/14786449708620994

To link to this article: http://dx.doi.org/10.1080/14786449708620994

$$
\text { 曲 Published online: } 08 \text { May } 2009 .
$$

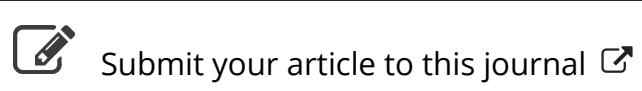

\footnotetext{
Џ Article views: 4
}

Q View related articles $\sqsubset$ 


\section{[ 291$]$}

XLI. The Heats of Vaporization of Liquids. By S. RosLInGTon Milner, B.Sc., 1851 Exhibition Scholar, University College, Bristol*.

$\mathrm{T} \mathrm{T}$ is well known that at the surface of a liquid in contact 1 with its vapour there exists, in consequence of the excess of the downward attraction of the molecules in the liquid over the upward attraction of those in the vapour part, a resultant downward pull on the thin surface-film, which is, of course, balanced by the ordinary hydrostatical variations of pressure and density. If we assume that no more degrees of freedom are opened up to the molecules in their passage from liquid to vapour, so that their average kinetic energies in the two conditions are the same, the difference in the potential energies of a gram of molecules, or the space integral of this surface-force per gram from the liquid to the vapour, may be taken as the same thing as the "internal" heat of vaporization (i.e. external work done excluded) expressed in mechanical units.

That with this assumption there must exist a definite relation between the heats of vaporization and the vapourdensities and temperatures of liquids may be seen at once by supposing the surface-film to be indefinitely thin. In this case it would follow that of the molecules striking against the surface of separation, only those whose kinetic energies resolved perpendicular to it were greater than the value of the above integral for a molecule would be able to pass through into the vapour. If the law of molecular motion in the liquid be known, the number passing per second into the vapour is thus a known function of the heat of vaporization; and evaporation goes on at this rate until the vapour-density reaches a stationary value such that the molecules pass back into the liquid at the same rate as they come out. Hence the value of the rapour-density at any temperature would be determined by its temperature and its latent heat.

The determinateness of this connexion it will be seen depends on the assumption that there is a difference only in degree, and not in kind, between a liquid and its vapourthat the only difference between the two, in fact, is that in the liquid the mean free path of the molecules is very small. However, the work of van der Waals has shown that this is approximately the case, and a relation obtained in this way may be expected to hold true to the same degree of appr'oximation.

* Communicated by the Author.

$\mathrm{Z} 2$ 
The actual calculation is more complicated than in the above simplified case in at least two respects. In the first place, instead of the liquid having an indefinitely thin surface, there must certainly in reality be a stratum of finite thickness in which the density varies continuously from that of the liquid to that of the vapour. Also, in dealing with liquids it is necessary to apply the corrections which van der Waals has indicated for the effect of the actual size of the molecules in altering their mean free paths.

With these modifications, consider therefore the region of varying density to be divided into infinitely thin layers of thickness $d z$, in passing upward through the boundary between two of which a molecule receives a sudden increase $d \phi$ in its mechanical potential, by doing work against the downward force. Putting $\mathrm{N}$ the number of molecules per c.c. of the liquid in the lower layer, we have

$$
\mathrm{N} d \phi={ }^{\top} \rho d \mathrm{~L}_{i}, \text {. . . . . . }
$$

where $d \mathrm{~L}_{i}$ is the element of internal latent heat per gram between the two layers, and $\rho$ the density of the liquid at this point.

If there were no collisions among the molecules, the minimum velocity, $v_{1}$, which a molecule must have in order to pass upwards through the boundary plane of the layers, would be given by the condition that its kinetic energy perpendicular to the plane must be equal to $d \phi$, or

$$
\frac{1}{2} m v_{1}^{2} \cos ^{2} \theta=d \phi
$$

in which $m$ is the mass, and $\theta$ the angle the direction of motion makes with the perpendicular to the plane.

As a matter of fact, however, collisions take place; and after a collision the molecule struck moves on from a position in advance of the centre of the striking molecule by an amount which (at constant temperature) is on the average a constant fraction of the distance between the centres of the molecules at impact. If $s$ be this distance, and $l$ the mean free path, then as van der Waals has shown *,

$$
\frac{l-s}{l}=\frac{v-b}{v}, \ldots . . . \quad \text {. }
$$

where $v$ is the volume of a gram of the liquid, and $b$ a

* Continuity of State: Phys. Soc. Translation, p. 374. $l$ is the mean free path calculated by neglecting the effect of the extension of the molecules in the direction of their relative motion. 
quantity proportional to the total volume of the molecules it contains.

A molecule moving up to the boundary plane at an angle $\theta$ to its perpendicular would experience in passing through a layer $d z, d z / l \cos \theta$ collisions. We may determine the effect of a collision by assuming that the molecule struck takes up a similar motion to that of the striking one at an average distance $s$ in advance of it in the line of motion. But this distance $s$ in a direction $\theta$ with the perpendicular to the plane is accomplished without motion against the molecular forces, so that for each collision the work necessary for the molecule to do in moving upwards may be considered to be diminisbed by

$$
s \cos \theta \frac{d \phi}{d z} .
$$

The minimum kinetic energy a molecule must have to pass upwards through the division plane of the layers, may therefore be written

$$
\frac{1}{2} m v_{1}^{2} \cos ^{2} \theta=d \phi-\frac{s}{l} d \phi=d \phi . \frac{v-b}{v} . . .
$$

by (2). Eliminating $d \phi$ between (1) and (3), we obtain, since $\mathrm{N} m=\rho$,

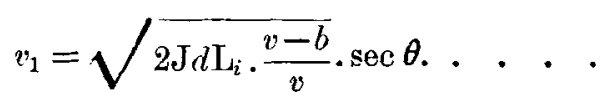

If we now take the motion of the molecules of the liquid to be that given by Maxwell's law of velocities, the number of molecules per c.c. of the layer $d z$, moving with velocities between $q$ and $q+d q$, and in directions making angles between $\theta$ and $\theta+d \theta$ with the perpendicular to the boundary plane, is

$$
\frac{2 \mathrm{~N}}{\sqrt{\pi \alpha^{3}}} \sin \theta \cdot q^{2} e^{-q^{2} / \alpha^{2}} d q d \theta, \quad . \quad . \quad . \quad \text {. }
$$

where $\alpha$ is the "velocity of maximum number" of the molecules. If there were no collisions the number of these striking against the boundary plane of the layers per second would be obtained by multiplying this expression by $q \cos \theta$. The effect of the collisions may, however, be determined as before, by assuming that for every distance $l-s$ that a molecule moves, another molecule takes up its motion at a distance $s$ in advance of it. The apparent velocity with 
which the molecules move towards the plane will therefore be increased in the ratio $\frac{l}{l-s}$ or $\frac{v}{v-b}$.

Multiplying (5), therefore, by $q \cos \theta \frac{v}{v-b}$ and integrating, we find for the number of molecules striking the division plane of the layers per second from below, and passing through it into the upper one,

$$
\mathrm{N}_{1}=\frac{2 \mathrm{~N}}{\sqrt{\pi} \alpha^{3}} \cdot \frac{v}{v-b} \int_{0}^{\pi / 2} \int_{v_{1}}^{\infty} \sin \theta \cos \theta q^{3} e^{-q^{2} / \alpha^{2}} d q d \theta, .
$$

in which the lower limit of $q$ is the $v_{1}$ of (4). The integration in $q$, which must be performed first, since $v_{1}$ is a function of $\theta$, gives

$$
\mathrm{N}_{1}=\frac{\mathrm{N}}{\sqrt{\pi} \alpha} \cdot \frac{v}{v-b} \int_{0}^{\pi / 2} e^{-\frac{2 J d \mathrm{~L}_{i}}{a^{2}} \cdot \frac{v-b}{v} \sec ^{2} \theta}\left\{\alpha^{2} \sin \theta \cos \theta+2 \mathrm{~J} d \mathrm{~L}_{i} \frac{v-b}{v} \tan \theta\right\} d \theta,
$$

which on further integration reduces to

$$
\mathrm{N}_{1}=\frac{\mathrm{N} \alpha}{2 \sqrt{\pi}} \cdot \frac{v}{v-b} e^{\frac{-2 J d \mathrm{~L}_{i} \cdot}{\alpha^{2}} \cdot \frac{v-b}{v}} . . . . .
$$

In the upper layer, the number of molecules per c.c. has become $\mathrm{N}-d \mathrm{~N}$, and the specific volume $v+d v$, and all the molecules which strike the boundary plane from above pass through it into the layer below. The number doing this per sec. is therefore,

or

$$
\mathrm{N}_{2}=\frac{2(\mathrm{~N}-d \mathrm{~N})}{\sqrt{\pi} \cdot \alpha^{3}} \cdot \frac{v+d v}{v+d v-b} \int_{0}^{\pi / 2} \int_{0}^{\infty} \sin \theta \cos \theta q^{3} e^{-q^{2} / \alpha^{2}} d q d \theta,
$$

$$
\mathrm{N}_{2}=\frac{(\mathrm{N}-d \mathrm{~N}) \alpha}{2 \sqrt{\pi}} \cdot \frac{v+d v}{v+d v-b}, \quad . . .
$$

where $\alpha$ is assumed to have the same value as before.

The total number passing through the boundary plane in either direction must be zero when the vapour is saturated, hence $\mathrm{N}_{1}=\mathrm{N}_{2}$, and equating the right-hand sides of (7) and (8),

since

$$
e^{\frac{2 \mathrm{~J} d \mathrm{~L}_{i}}{a^{2}} \cdot \frac{v-b}{v}}=\frac{v+d v-b}{v-b},
$$

$$
\mathrm{N} /(\mathrm{N}-d \mathrm{~N})=(v+d v) / v \text {. }
$$

Taking logarithms and expanding, and writing for $\alpha^{2}$ its value $\frac{2}{3} \overline{q^{2}}$, or $\frac{2 \mathrm{R} T}{\mathrm{M}}$, where $\mathrm{R}$ is the ordinary gas constant 
$(=1.979 \mathrm{~J})$, and $\mathrm{M}$ the molecular weight of the liquid, we have

$$
d \mathrm{~L}_{i}=\frac{\mathrm{RT}}{\mathrm{JM}} \frac{v d v}{(v-b)^{\underline{q}}},
$$

or integrating from the interior of the liquid to that of the vapour,

$$
\mathrm{L}_{i}=\frac{\mathrm{R}^{\prime} \mathrm{T}}{\mathrm{JM}}\left\{\log \frac{v^{\prime}-b}{v-b}+\frac{b}{v-b}-\frac{b}{v^{\prime}-b}\right\}, .
$$

in which $v$ and $v^{\prime}$ are the specific volumes of the liquid and saturated vapour respectively.

By the method of its derivation, eq. (9) is general, and gives the relation between the specific volumes and the differences of potential $\mathrm{JL}_{i}$, due to any system of bodily forces acting on a vapour the size of whose molecules is not negligible compared with their free paths.

The assumptions employed above as to the effect produced by the volume of the molecules are the same as those which lead to van der Waals's characteristic equation for fluids :

$$
\left(p+\frac{a}{v^{2}}\right)(v-b)=\frac{\mathrm{RT}}{\mathrm{M}} .
$$

Equation (9) may therefore also be derived from this, and the ordinary bydrostaticul equations of equilibrium in a somewhat simpler way, although this gives no account of the molecular autions which constitute the process.

As the assumptions involved in the term $\frac{a}{v^{2}}$ are not necessary, let

$$
p(v-b)=\frac{\mathrm{RT}}{\mathrm{M}} \quad \cdot \quad \cdot .
$$

be the relation between the pressure and volume of the fluid in the region of varying density, $-p$ being the actual pressure (molecular included with external). $b$ may be not necessarily independent of the temperature, but if it be not variable with $v$, we can differentiate $(10)$ at constant temperature und obtain

$$
d p(v-b)+\frac{\mathrm{RT}}{\mathrm{M}} \cdot \frac{d v}{v-b}=0 . . . .
$$

The ordinary equation of hydrostatical equilibrium in the surface-film is

$$
d p=\rho d \mathrm{~V}, \cdot \text {. . . . . }
$$

where $d \mathrm{~V}$ is the element of potential of the bodily forces on the liquid, and $\rho$ the density. Substituting for $d p$ from (11), 
and integrating from the interior of the liquid to that of the vapour, we obtain

$$
\mathrm{V}^{\prime}-\mathrm{V}=\frac{\mathrm{RT}}{\mathrm{M}} \int_{0}^{v^{\prime}} \frac{v d v}{(v-b)^{2}}
$$

which, with $\mathrm{JL}_{i}$ written for $\mathrm{V}^{\prime}-\mathrm{V}$, is the same equation as (9) for the internal heat of vaporization.

Another expression for the latent heat might similarly be obtained from the other term of tho characteristic equation by writing the pressure in the liquid as

$$
p=p^{\prime}+\frac{a}{v^{2}}, \quad p^{\prime} \text { being the vapour-pressure. }
$$

In the film of varying density, $p$ would also contain terms depending on $\frac{d v}{d z}$; but on integration between places where the densities are constant these would vanish from the final result, and the internal latent heat would become *

$$
\frac{1}{\mathrm{~J}} \int_{v}^{v} \frac{d p}{\rho} \text {, by }(12)=\frac{1}{J} \cdot 2 a\left(\frac{1}{v}-\frac{1}{v^{\prime}}\right) . \quad .
$$

* It seems to have been usual to assume that the total latent heat of a rapour is given by $\int_{v}^{v^{\prime}} p d v$. Thus Nernst ('Theoretical Chemistry,' p. 209), writing the pressure in the liquid

$$
p=p^{\prime}+\frac{a}{v^{2}},
$$

makes the internal heat of vaporization

$$
\frac{1}{\mathrm{~J}} \int_{v}^{v^{\prime}} \frac{a}{v^{2}} d v=\frac{a}{\mathrm{~J}}\left(\frac{1}{v}-\frac{1}{v^{\prime}}\right)
$$

a result only half as great as (13). Consideration of the process, however, seems to show that the internal heat is the same thing as the difference of potential $V^{\prime}-V$, and that therefore its value is given by $\int_{v}^{v^{\prime}} \frac{d p}{\rho}$ or $\int_{v}^{v^{\prime}} v d p$. For the molecules in moving from the liquid to the vapour and doing work against the molecular forces change their kinetic energies by an amount $V^{\prime}-V$, or $\int v d p$ per gram into potential energy. This amount of heat is therefore taken from the system, and remains in the vapour as potential energy. At the same time, as thisy move up through the region of varying density, they expand and lose kinetic energy $=\int p d v$ (although it is not necessary for a molecule to bave the extra energy indicated by this to be able to pass from one layer to the next considered in the deduction of $(9)$ - the expansion may be considered 
This expression, bowever, does not seem to give very accurate results; it is of a different form from (9), altbough of course were van der Wials's equation strictly true it would be equivalent to it.

Equation (9) for the beat of vaporization contains what is to a certain extent an arbitrary constant $b . \quad b$ is not, however, in reality completely arbitrary, as it can be calculated approximately from the critical volume, although the approximation is very rough, or it could, if necessary, be estimated with sufficient exactness by substituting in van der Waals's equation the specific volumes of the liquid at two different pressures. $\mathrm{As}$, however, there seems some theoretical reason to believe that $b$ is slightly variable with the temperature*, it seems better, instead of calculating the heats of vaporization of different liquids with approximate values of $b$, to test the formula by calculating $b$ for different temperatures of the same liquid from the other quantities of the equation, either to see if it keeps constant or to determine its variation. The values obtained in this way may be tested by applying them in the equation

$$
\left(p+\frac{a}{v^{2}}\right)(v-b)=\frac{\mathrm{RT}}{\mathrm{M}}
$$

to see if they give satisfactorily constant values of $a$ (this equation being used here for the liquid state only, where it holds very approximately, although the constant may change considerably through such a large range as that from the liquid to the vapour).

The only two cases in which the heats of vaporization have been measured with any accuracy at different temperatures are water and benzene. Below are the values of $b$ and $a$ calculated for these substances by means of (9), the headings of the columns denoting the quantities expressed by those letters in the earlier part of the paper. (Volumes are given in c.cs., the latent heat in gr. calories, and $a$ is in units such that $\frac{a}{v^{2}}$
is a pressure in dynes per sq. $\mathrm{cm}$.)

as going on after the polecules have reached the upper layer). The work $\int p d v$ done in this way, however, goes to increase the kinetic energies of other molecules of the system, and is immediately made up to the expanding molecules by radiation, so that the system as a whole does not lose this heat. If part of this work to the extent $p\left(v^{\prime}-v\right)$ is done on the atmosphere, as when evaporation is actively going on, it must of course be supplied to the liquid as extra heat.

* Sutherland, Phil. Mag vol. xxxvi. (1893) p. 507. 
Water.

\begin{tabular}{|c|c|c|c|c|c|}
\hline$t$ & $v$. & $v^{\prime}$ & $\mathbf{L}_{i}$ & $b$. & a. \\
\hline $\begin{array}{r}0 \\
25 \\
50 \\
75 \\
100 \\
125\end{array}$ & $\begin{array}{l}1.000 \\
1.003 \\
1.012 \\
1.026 \\
1.043 \\
1.062\end{array}$ & $\begin{array}{c}210600 \\
43960 \\
12050 \\
4102 \\
1650 \\
755.5\end{array}$ & $\begin{array}{l}575 \cdot 7 \\
556 \cdot 0 \\
536 \cdot 0 \\
516 \cdot 3 \\
496 \cdot 5 \\
477 \cdot 0\end{array}$ & $\begin{array}{r}0.838 \\
\cdot 822 \\
\cdot 813 \\
.803 \\
.799 \\
.794\end{array}$ & $\begin{array}{l}7 \cdot 76 \times 10^{9} \\
7 \cdot 71 \\
7 \cdot 66 \\
7 \cdot 57 \\
7 \cdot 66 \\
7 \cdot 72\end{array}$ \\
\hline
\end{tabular}

Benzene, $\mathrm{C}_{6} \mathrm{H}_{6}$. Mol. wt. 77·84.

\begin{tabular}{|c|c|c|c|c|c|}
\hline$t$ & $v$ & $v^{\prime}$ & $\mathrm{L}_{i}$ & b. & $a$. \\
\hline $0 \cdot 2$ & $1 \cdot 1113$ & 8141 & $100 \cdot 10$ & 0.8852 & $1.66 \times 10^{9}$ \\
\hline $17 \cdot 3$ & $1 \cdot 1341$ & 3523 & 96.96 & .8864 & $1.605^{\lambda+v}$ \\
\hline 32.0 & $1 \cdot 1544$ & 1874 & $94 \cdot 30$ & $\cdot 8862$ & 1.614 \\
\hline $48 \cdot 4$ & $1 \cdot 1784$ & 1001 & $91 \cdot 32$ & $\cdot 8862$ & 1.628 \\
\hline 67.0 & $1 \cdot 2070$ & $538 \cdot 0$ & 80.01 & $\cdot 8854$ & $1 \cdot 640$ \\
\hline 86.4 & $1 \cdot 2382$ & $304 \cdot 7$ & $84: 57$ & $\cdot 88.35$ & 1654 \\
\hline 956 & $1 \cdot 2541$ & $238 \cdot 3$ & 82.94 & $\cdot 8830$ & $1 \cdot 666$ \\
\hline 1104 & 1.2812 & 164.2 & $80 \cdot 39$ & $\cdot 8837$ & $1 \cdot 682$ \\
\hline $121 \cdot 6$ & $1 \cdot 3037$ & $126 \cdot 7$ & 78.55 & $\cdot 8848$ & $1 \cdot 697$ \\
\hline
\end{tabular}

The latent heats have been calculated from the empirical formulx

$$
\begin{aligned}
& \text { Water . } \mathrm{L}_{i}=606.5-0.70 t-\frac{p\left(v^{\prime}-v\right)}{\mathrm{J}}, \\
& \text { Benzene }^{*} \cdot \mathrm{L}_{i}=107.05-0.158 t-\frac{p\left(v^{\prime}-v\right)}{\mathrm{J}} .
\end{aligned}
$$

It will be seen that these cases, the only two in which the latent heats have been measured experimentally, give opposite results as regards the constancy of the numbers $b$ and $a$. In water, while $b$ show's a gradual decrease of about 5 per cent. in $125^{\circ}, a$ remains fairly constant; in benzene $b$ seems to remain constant, while $a$ increases. The regularity of the variation of the numbers (such as the fall to a minimum with subsequent increase in $a$ in water) is due to the fact that $\mathrm{L}_{i}$ has been calculated from an empirical formula the constants of which may not be quite accurate. The increase at high temperatures in the value of $b$ for benzene is also due to extrapolating the empirical formula for $\mathrm{L}_{i}$ too far. The measurements of Griffiths and Marshall extended only up to $40^{\circ}$, so that the constancy of $b$ at higher temperatures may be considered doubtful, since the linear form of their equation may * Griffiths and Marshall, Phil. Mag. January 1896. 
not hold above $40^{\circ}$. To obtain more reliable values at higher temperatures, I have calculated the latent heats of benzene by means of Clausius's equation,

$$
\mathrm{I}_{i}=\frac{1}{\mathrm{~J}}\left(v^{\prime}-v\right)\left(\mathrm{T} \frac{d p}{d t}-p\right),
$$

by which the latent heat may be obtained up to the critical point. By this means one may calculate the latent heats at different temperatures of some other substances for which they have not been experimentally measured, but in which $v, v^{\prime}$, and $p$ are known, and so obtain a fair number of cases by which to test the validity of (9). The data have been obtained almost completely from papers by Ramsay and Young, or Young and Thomas, in the Philosophical Magazine, Philosophical Transactions, and Journal of the Chemical Society.

The values of $\frac{d p}{d t}$ and of $\mathrm{L}$ have been given in one or two cases by the observers, being obtained from an empirical equation for the vapour-pressure. In the other cases $\frac{d p}{d t}$ has been determined by tabulating the differences in $\log _{10} p$ for $20^{\circ}$ (the curve for $\log p$ being nearly a straight line, tbese differences do not differ greatly from the differential coefficients), and calculating $\frac{d p}{d t}$ from them by the relation

$$
\frac{d p}{d t}=p \cdot \frac{\delta_{20} \log _{i 0} p}{20} \cdot \frac{1}{0 \cdot 4343},
$$

a method which gives $d p / d t$ somewhat more accurately than taking differences on the vapour-pressure curve itself. The values of the latent heats have generally been smoothed by a curve before using in the equation for $b$.

Below are given the values of $b$ and $a$ for a number of substances, with $\mathrm{L}_{i}$ determined in this way.

\begin{tabular}{|c|c|c|c|c|c|}
\hline$t$ & $v$ & $\boldsymbol{v}^{\prime}$ & $L_{i}$. & b. & a. \\
\hline $\begin{array}{r}0 \cdot 2 \\
17 \cdot 3 \\
32 \cdot 0 \\
48 \cdot 4 \\
67 \cdot 0 \\
110 \cdot 4 \\
163 \cdot 4 \\
181 \cdot 4 \\
202 \cdot 3\end{array}$ & $\begin{array}{l}1 \cdot 1113 \\
1 \cdot 1341 \\
1 \cdot 1544 \\
1 \cdot 1784 \\
1 \cdot 2070 \\
1 \cdot 2812 \\
1 \cdot 4008 \\
1 \cdot 4523 \\
1.5225\end{array}$ & $\begin{array}{c}8141 \\
3523 \\
1874 \\
1001 \\
538 \cdot 0 \\
164 \cdot 2 \\
53 \cdot 93 \\
38 \cdot 84 \\
26 \cdot 97\end{array}$ & $\begin{array}{r}101 \cdot 0 \\
98 \cdot 7 \\
95 \cdot 9 \\
92 \cdot 9 \\
89 \cdot 0 \\
80 \cdot 1 \\
68 \cdot 3 \\
64 \cdot 0 \\
59 \cdot 0\end{array}$ & $\begin{array}{r}0.8900 \\
8962 \\
8970 \\
8975 \\
.8910 \\
8820 \\
.8600 \\
8512 \\
.8490\end{array}$ & $\begin{array}{l}1 \cdot 671 \times 10^{9} \\
1.682 \\
1.690 \\
1.683 \\
1.675 \\
1.673 \\
1.677 \\
1 \cdot 707\end{array}$ \\
\hline
\end{tabular}

Benzene. 
It will be seen that the latent heats calculated from Clausius's equation are slightly different from those given by Griffiths and Marshall, so that while $b$ diminishes considerably at high temperatures, its substitution in van der Waals's equation gives a very constant value of $a$ through a wide range of temperature. The calculation of $b$ becomes very uncertain at low and at high temperatures, so that no reliance can be placed on the result at $202^{\circ} 3 ; b$ would have to be still smaller than it is to bring $a$ down to the normal value.

Ethyl Oxide, $\left(\mathrm{C}_{2} \mathrm{H}_{5}\right)_{2} \mathrm{O}$. Mol. wt. 84.0.

\begin{tabular}{|c|c|c|c|c|c|}
\hline$t$ & $v$ & $v^{\prime}$ & $\mathbf{L}_{i}$. & $b$. & $a$. \\
\hline $\begin{array}{r}0 \\
20 \\
40 \\
60 \\
80 \\
100 \\
120 \\
140 \\
160 \\
170 \\
180 \\
190\end{array}$ & $\begin{array}{l}1 \cdot 358 \\
1 \cdot 401 \\
1 \cdot 451 \\
1 \cdot 502 \\
1 \cdot 562 \\
1.638 \\
1.735 \\
1.857 \\
2 \cdot 021 \\
2 \cdot 147 \\
2 \cdot 343 \\
2 \cdot 730\end{array}$ & $\begin{array}{c}1209 \\
53 \pm 7 \\
2(68 \cdot 0 \\
147 \cdot 7 \\
86 \cdot 60 \\
53 \cdot 55 \\
34 \cdot 09 \\
22 \cdot 28 \\
14 \cdot 47 \\
11 \cdot 45 \\
8 \cdot 815 \\
6 \cdot 172\end{array}$ & $\begin{array}{l}86 \cdot 16 \\
80 \cdot 44 \\
75 \cdot 36 \\
70 \cdot 81 \\
65.91 \\
60 \cdot 32 \\
54 \cdot 90 \\
47 \cdot 32 \\
39 \cdot 75 \\
34 \cdot 16 \\
27 \cdot 09 \\
18 \cdot 11\end{array}$ & $\left.\begin{array}{c}1.054 \\
1.043 \\
1.038 \\
1.031 \\
1.025 \\
1.012 \\
1.015 \\
0.977 \\
.977 \\
.951 \\
.912 \\
.976\end{array}\right\} ?$ & $\begin{array}{l}1.803 \times 10^{9} \\
1.790 \\
1.786 \\
1.793 \\
1.778 \\
1.816 \\
1.768 \\
1.818 \\
1.803\end{array}$ \\
\hline
\end{tabular}

Methyl Alcohol, $\mathrm{CH}_{3} \mathrm{OH}$. Mol. wt. 31·92.

\begin{tabular}{|c|c|c|c|c|c|}
\hline$t$ & $v$. & $v^{\prime}$. & $\mathbf{L}_{i}$ & $b$. & a. \\
\hline $\begin{array}{r}20 \\
40 \\
60 \\
80 \\
100 \\
120 \\
140 \\
100 \\
180 \\
190 \\
200 \\
210\end{array}$ & $\begin{array}{l}1.265 \\
1.291 \\
1.324 \\
1.360 \\
1.401 \\
1.449 \\
1.506 \\
1.577 \\
1.672 \\
1.733 \\
1.808 \\
1.903\end{array}$ & $\begin{array}{c}5899 \\
2276 \\
993 \cdot 8 \\
479 \cdot 8 \\
251 \cdot 0 \\
140 \cdot 0 \\
82 \cdot 25 \\
50 \cdot 16 \\
31 \cdot 40 \\
24 \cdot 94 \\
19 \cdot 70 \\
15 \cdot 33\end{array}$ & $\begin{array}{l}266.5 \\
258.9 \\
249 \cdot 6 \\
2386 \\
225.2 \\
2110 \\
195.3 \\
178 \cdot 2 \\
158 \cdot 2 \\
147.4 \\
134.9 \\
119.5\end{array}$ & $\begin{array}{l}1.086 \\
1.043 \\
1.052 \\
1.060 \\
1.063 \\
1.066 \\
1.065 \\
1.065 \\
1.065 \\
1.066 \\
1.065 \\
1.055\end{array}$ & $\begin{array}{l}5.32 \times 10^{9} \\
5 \cdot 46 \\
5 \cdot 57 \\
5 \cdot 64 \\
5 \cdot 62 \\
5.58 \\
5.51 \\
5 \cdot 45 \\
5 \cdot 35 \\
5 \cdot 32 \\
5.40\end{array}$ \\
\hline
\end{tabular}


Stannic Chloride, $\mathrm{SnCl}_{4}$. Mol. wt. 259.3.

\begin{tabular}{|c|c|c|c|c|c|}
\hline$t$ & $v$ & $v^{\prime}$ & $\mathbf{L}_{i}$ & $b$ & $a$. \\
\hline 140 & 0.5243 & 61.9 & 26.0 & 0.314 & $2 \cdot 26 \times 10^{*}$ \\
\hline 160 & 5411 & 59.9 & 245 & .363 & $2 \cdot 26$ \\
\hline 180 & .5595 & 266 & 230 & $\cdot 359$ & $2 \cdot 25$ \\
\hline 200 & .5800 & 18.35 & $21 \cdot 5$ & 356 & 224 \\
\hline 220 & .6065 & 12.44 & 200 & 357 & 228 \\
\hline 340 & 6383 & 9.23 & 18.2 & -354 & 229 \\
\hline 260 & 6781 & 658 & 160 & $3+7$ & $2 \cdot 28$ \\
\hline 280 & 7338 & 463 & 132 & .395 & $2 \cdot 26$ \\
\hline
\end{tabular}

Methyl Formate, $\mathrm{HCOOCH}_{3}$. Mol. wt. 59:86.

\begin{tabular}{|c|c|c|c|c|c|}
\hline$t$ & $v$ & $\boldsymbol{v}^{\prime}$. & $\mathrm{I}_{i}$. & b. & $a$. \\
\hline $\begin{array}{r}60 \\
80 \\
100 \\
120 \\
140 \\
160 \\
180 \\
200\end{array}$ & $\begin{array}{l}1 \cdot 0949 \\
1 \cdot 1360 \\
1 \cdot 1831 \\
1 \cdot 2392 \\
1 \cdot 3092 \\
1 \cdot 4013 \\
1 \cdot 5336 \\
1 \cdot 7675\end{array}$ & $\begin{array}{c}167 \cdot 0 \\
95 \cdot 05 \\
58 \cdot 45 \\
37 \cdot 25 \\
24 \cdot 25 \\
16 \cdot 05 \\
10 \cdot 60 \\
6.56\end{array}$ & $\begin{array}{l}96 \cdot 2 \\
87 \cdot 8 \\
82 \cdot 0 \\
791 \\
75 \cdot 5 \\
689 \\
48 \cdot 0 \\
34 \cdot 0\end{array}$ & $\begin{array}{l}0.7760 \\
.7590 \\
.7560 \\
.7475 \\
.7390 \\
.7130 \\
.6880 \\
.6650\end{array}$ & $\begin{array}{l}1 \cdot 732 \times 10^{9} \\
1.668 \\
1.682 \\
1 \cdot 681 \\
1 \cdot 688 \\
1 \cdot 660 \\
1 \cdot 650 \\
1 \cdot 687\end{array}$ \\
\hline
\end{tabular}

Ethyl Formate, $\mathrm{HCOOC}_{2} \mathrm{H}_{5}$. Mol. wt. 73.83 .

\begin{tabular}{|c|c|c|c|c|c|}
\hline$t$. & $v$. & $v^{\prime}$. & Li. & b. & \multicolumn{1}{|c|}{$a}$. \\
\hline 100 & 1.2327 & 97.0 & 76.88 & 0.8455 & $1.638 \times 10^{9}$ \\
120 & 1.2827 & 60.4 & 71.33 & -8384 & 1.625 \\
140 & 1.3427 & 39.1 & 6564 & .8326 & 1.62 .2 \\
160 & 1.4169 & 25.8 & 58.89 & -8194 & 1.606 \\
180 & 1.5129 & 17.4 & 50.69 & 7900 & 1.560 \\
200 & 16484 & 11.60 & 42.50 & 7680 & 1.563 \\
220 & 1.8902 & $7 \cdot 25$ & 30.14 & 7485 & 1.597 \\
\hline
\end{tabular}

Methyl Acetate, $\mathrm{CH}_{3} \mathrm{COOCH}_{3}$. Mol. wt. 73.83.

\begin{tabular}{|c|c|c|c|c|c|}
\hline$t$. & $v$ & $v^{\prime}$ & $\mathbf{L}_{i .}$ & $b$, & $a$. \\
\hline $\begin{array}{l}100 \\
120 \\
140 \\
160 \\
180 \\
200 \\
220\end{array}$ & $\begin{array}{l}1.2163 \\
1 \cdot 2670 \\
1.3276 \\
1.4020 \\
1.4991 \\
1.6393 \\
1.8936\end{array}$ & $\begin{array}{c}1035 \\
63.4 \\
407 \\
26.80 \\
17.60 \\
11.55 \\
7.06\end{array}$ & $\begin{array}{l}79 \cdot 67 \\
73 \cdot 87 \\
67 \cdot 78 \\
61 \cdot 22 \\
53 \cdot 22 \\
43.72 \\
30 \cdot 43\end{array}$ & $\begin{array}{r}0.8519 \\
.8478 \\
.8421 \\
.8370 \\
.83: 9 \\
.8067 \\
.7780\end{array}$ & $\begin{array}{l}1.694 \times 10^{9} \\
1.680 \\
1.663 \\
1.634 \\
1.648 \\
1.639 \\
1.660\end{array}$ \\
\hline
\end{tabular}


Propyl Formate, $\mathrm{HCOOC}_{3} \mathrm{H}_{7}$. Mol. wt. $87 \cdot 80$.

\begin{tabular}{|c|c|c|c|c|c|}
\hline$t$. & $v$. & $v^{\prime}$ & $I_{i .}$ & $b$ & a. \\
\hline $\begin{array}{r}80 \\
100 \\
120 \\
140 \\
160 \\
180 \\
200 \\
220 \\
240\end{array}$ & $\begin{array}{l}1 \cdot 199 \\
1.238 \\
1.280 \\
1.329 \\
1.387 \\
1 \cdot 455 \\
1 \cdot 542 \\
1.660 \\
1.839\end{array}$ & $\begin{array}{r}325 \\
184 \\
111.5 \\
70.4 \\
45.9 \\
30.9 \\
21.2 \\
14.5 \\
9.6\end{array}$ & $\begin{array}{l}79 \cdot 3 \\
75 \cdot 3 \\
70 \cdot 5 \\
66 \cdot 7 \\
6 \mathrm{I} \cdot 1 \\
54 \cdot 5 \\
49 \cdot 0 \\
49 \cdot 4 \\
34 \cdot 3\end{array}$ & $\left.\begin{array}{c}0.898 \\
899 \\
893 \\
.899 \\
.888 \\
860 \\
-856 \\
.849 \\
860\end{array}\right\} ?$ & $\begin{array}{l}1.59 \times 10^{9} \\
1.59 \\
1.56 \\
1.59 \\
1.56 \\
1.51 \\
1.52 \\
1.52 \\
1.58\end{array}$ \\
\hline
\end{tabular}

Ethyl Acetate, $\mathrm{CH}_{3} \mathrm{COOC}_{2} \mathrm{H}_{5}$. Mol. wt. $87 \cdot 80$.

\begin{tabular}{|c|c|c|c|c|c|}
\hline$t$ & $v$. & $v^{\prime}$ & $\mathrm{L}_{i}$ & b. & a. \\
\hline $\begin{array}{r}80 \\
100 \\
120 \\
140 \\
160 \\
180 \\
200 \\
220\end{array}$ & $\begin{array}{l}1.213 \\
1.254 \\
1.302 \\
1.355 \\
1.422 \\
1.503 \\
1.610 \\
1.770\end{array}$ & $\begin{array}{l}285 \\
162 \\
97 \cdot 0 \\
60 \cdot 6 \\
38 \cdot 8 \\
25 \cdot 75 \\
17 \cdot 25 \\
11 \cdot 23\end{array}$ & $\begin{array}{l}77 \cdot 4 \\
74 \cdot 5 \\
70 \cdot 0 \\
65 \cdot 2 \\
58 \cdot 4 \\
52 \cdot 1 \\
45 \cdot 5 \\
37 \cdot 5\end{array}$ & $\begin{array}{r}0.903 \\
.916 \\
.918 \\
.918 \\
.900 \\
.887 \\
.886 \\
.885\end{array}$ & $\begin{array}{l}1.58 \times 10^{9} \\
1.63 \\
1.63 \\
1.63 \\
1.57 \\
1.55 \\
1.56 \\
1.57\end{array}$ \\
\hline
\end{tabular}

It will be seen by inspection of the tables, that while the value of $b$ calculated from the heat of vaporization by equation (9) as a rule diminishes fairly considerably with the temperature, that of a determined by its substitution in van der Waals's equation remains approximately, and in some cases very accurately constant. 'The experimental quantities in the last two or three cases seem somewhat less accurate than in the others, and the numbers $b$ obtained from them do not lie at all well on a curve-and as $a$ shows itself very sensitive to the slightest changes in $b$, its values here show somewhat large divergences. Still an inspection of the numhers at low and at high temperatures shows that the considerable diminution in $b$ that takes place is of such an amount as to make the $a$ determined from it approximately constant. The slow fall to a minimum and subsequent rise of $a$ in some cases may be due either to some extent to experimental inaccuracy, or more probably to equation (9) not holding completely through a wide range of temperature,-as, indeed, with its assumptions it can bardly be expected to do. 
Several other substances tried give a similar diminution of $b$ and constancy of $a$. I have only come across two so far which have failed to do so, propyl alcohol and carbon tetrachloride. In the first of these $a$ shows a gradual and continuous decrease, and in the second an increase, for which it is difficult to see any reason. It may be as well to give the data for these substances:-

Propyl Alcohol, $\mathrm{C}_{3} \mathrm{H}_{7} \mathrm{OH}$. Mol. wt. 59・86.

\begin{tabular}{|c|c|c|c|c|c|}
\hline$t$. & $v_{*}$ & $v^{\prime}$ & $\mathbf{I}_{i .}$ & $b$. & a. \\
\hline $\begin{array}{r}80 \\
100 \\
120 \\
140 \\
160 \\
180 \\
200 \\
220\end{array}$ & $\begin{array}{l}1.330 \\
1.365 \\
1.406 \\
1.455 \\
1.515 \\
1.591 \\
1.689 \\
1.823\end{array}$ & $\begin{array}{l}958 \cdot 0 \\
443 \\
225 \\
124 \\
72 \cdot 3 \\
44 \cdot 5 \\
28: 3 \\
18 \cdot 0\end{array}$ & $\begin{array}{r}161 \cdot 5 \\
152 \cdot 1 \\
141 \cdot 0 \\
130 \cdot 4 \\
117 \cdot 1 \\
104 \cdot 8 \\
91 \cdot 4 \\
75 \cdot 7\end{array}$ & $\begin{array}{l}1 \cdot 120 \\
1 \cdot 130 \\
1 \cdot 132 \\
1 \cdot 137 \\
1 \cdot 132 \\
1 \cdot 139 \\
1 \cdot 120 \\
1 \cdot 095\end{array}$ & $\begin{array}{l}4.12 \times 10^{9} \\
4.09 \\
3.93 \\
3.81 \\
3.60 \\
3 \cdot 52 \\
3.30 \\
3 \cdot 12\end{array}$ \\
\hline
\end{tabular}

Carbon Tetrachloride, $\mathrm{CCl}_{4}$. Mol. wt. 153*45.

\begin{tabular}{|c|c|c|c|c|c|}
\hline$t$ & $v$. & $v^{\prime}$. & $L_{i}$ & b. & a. \\
\hline $\begin{array}{r}60 \\
80 \\
100 \\
120 \\
140 \\
160 \\
180 \\
200 \\
220 \\
240 \\
260\end{array}$ & $\begin{array}{r}0.6594 \\
.6773 \\
.6972 \\
.7193 \\
.7435 \\
.7703 \\
.8019 \\
.8412 \\
.8907 \\
.9575 \\
1.0628\end{array}$ & $\begin{array}{c}298 \cdot 2 \\
163 \cdot 5 \\
97 \cdot 5 \\
61 \cdot 2 \\
40 \cdot 3 \\
27 \cdot 4 \\
19 \cdot 05 \\
13 \cdot 48 \\
9 \cdot 62 \\
6 \cdot 83 \\
4 \cdot 66\end{array}$ & $\begin{array}{l}43 \cdot 0 \\
41 \cdot 2 \\
39 \cdot 55 \\
37 \cdot 76 \\
55 \cdot 76 \\
33 \cdot 50 \\
30 \cdot 90 \\
28 \cdot 20 \\
25 \cdot 31 \\
22 \cdot 02 \\
17 \cdot 18\end{array}$ & $\begin{array}{l}0.4765 \\
\cdot 4760 \\
\cdot 4757 \\
\cdot 4749 \\
\cdot 4720 \\
\cdot 4665 \\
\cdot 4565 \\
\cdot 4505 \\
\cdot 4460 \\
\cdot 4460 \\
\cdot 4370\end{array}$ & $\begin{array}{l}4.29 \times 10^{8} \\
4.33 \\
4 \cdot 42 \\
4 \cdot 48 \\
4.51 \\
+55 \\
4 \cdot 49 \\
4.54 \\
4.59 \\
4.72 \\
4 \cdot 71\end{array}$ \\
\hline
\end{tabular}

The examples given in the previous Tables seem sufficient to substantiate for the majority of liquids the validity of the assumptions on which the equation for the heat of vaporization is based. It is clear that, with the two exceptions mentioned, the internal heat of vaporization of these liquids will be accurately expressed by the equation

$$
\mathrm{L}_{i}=\frac{\mathrm{RT}}{\mathrm{JM}}\left\{\frac{1}{\cdot 4343} \log _{10} \frac{v^{\prime}-b}{v-b}+\frac{b}{v-b}-\frac{b}{v^{\prime}-b}\right\}, .
$$

in which $b$, although not constant, has a value satisfying 
van der Waals's equation,

$$
\left(p+\frac{a}{v^{3}}\right)(v-b)=\frac{\mathrm{RT}}{\mathrm{M}}, \text {. . . . }
$$

$v$ being the volume of the liquid, and $a$ an absolute constant.

This is not quite the same thing as if $b$ were eliminated between (9) and (14), which would give

$$
\mathrm{L}_{i}=\frac{\mathrm{RT}}{\mathrm{JM}} \log \frac{p+\frac{a}{v^{q}}}{p+\frac{a}{v^{\prime 2}}}+\frac{a}{J}\left(\frac{1}{v}-\frac{1}{v^{\prime}}\right)-\frac{1}{J} p\left(v^{\prime}-v\right),
$$

as there is reason to believe that $a$ varies a good deal from the liquid to the vapour, although it remains fairly constant in the liquid. However, at low temperatures, $a / v^{\prime 2}$ is negligible with regard to $p$, and $p$ with regard to $a / v^{2}$, so that in this case the total heat of vaporization would be sufficiently expressed by

$$
\mathrm{L}=\frac{\mathrm{RT}}{\mathrm{JM}} \log \frac{a}{p v^{2}}+\frac{a}{\mathrm{~J} v}
$$

(transferring $\frac{1}{J} p\left(v^{\prime}-v\right)$ to the left-hand side of the equation).

A calculation indeed shows that an equation of this form expresses it with considerable accuracy at low temperatures.

Finally, the equation for the heat of vaporization throws an interesting light on Trouton's well-known law that $\frac{\text { ML }}{\mathrm{T}}$ is roughly constant for different liquids, $L$ being the heat of vaporization at the absolute temperature $T$ of the boiling-point.

From equation (9) it will be seen that $\frac{M L}{T}$ is a quantity depending on $v, v^{\prime}$, and $b$. But $v^{\prime}$, which is the only quantity which would vary considerably from substance to substance, only enters in the logarithm, and in the denominator of a small term, and will consequently not greatly affect the result; again $\frac{b}{v}$, and therefore $\frac{b}{v-b}$, is not greatly different for different liquids at corresponding temperatures, which may be considered the same as their boiling-points. $\frac{\mathrm{ML}}{\mathrm{T}}$, therefore, at the boiling-point will not vary more than 20 or 30 per cent. for most liquids, which is about the extent to which Trouton's law applies. 